\title{
Princípios de suplementação mineral em ruminantes ${ }^{1}$
}

\author{
Paulo Vargas Peixoto ${ }^{2}$, Pedro Malafaia ${ }^{2}$, José Diomedes Barbosa ${ }^{3}$ e \\ Carlos Hubinger Tokarnia ${ }^{2}$
}

\begin{abstract}
Peixoto P.V., Malafaia P., Barbosa J.D. \& Tokarnia C.H. 2005. [Principles of mineral supplementation in ruminants.] Princípios de suplementação mineral em ruminantes. Pesquisa Veterinária Brasileira 25(3):195-200. Depto Nutrição Animal e Pastagem, Instituto de Zootecnia, UFRRJ, Km 47, Seropédica, RJ 23890-000, Brazil. E-mail: pfpeixoto@terra.com.br

Although there is solid knowledge on mineral deficiencies and their consequences on health and productivity of cattle in Brazil, paradoxically, those informations, most of the time, are not used by professionals of the agricultural sciences, who persist in stimulating the widespread use of the so-called complete mineral mixtures. The deficiency of many minerals included in these supplements, as iron, chrome, sulfur, and others, do not occur under natural conditions or only in rare and very particular situations. The present paper deals with the misunderstandings and problems related to traditional mineral supplementation and discusses the main aspects of the so-called selective mineral supplementation that is based in supplying exclusively the deficient mineral(s) and these only in necessary amounts. This procedure can result in expressive economy (sometimes up to $700 \%$ ) when compared with the commercial mineral supplementation usually employed. According to several estimates, mineral supplementation can account for 20 to $30 \%$ of the total cost of beef cattle production on tropical pastures. A reversion assay, in which a group of cattle receives the commercial mineral mixture routinely used on the farm, and another group which receives the selective supplement, is the best option for the elucidation of positive or negative effects between the two possibilities of mineral supplementation on a specific farm. Trough this assay, the effects of the two compositions of mineral supplements can be investigated rationally over a sufficient period of time, with no risks and minimal possibilities of economic losses.
\end{abstract}

INDEX TERMS: Mineral deficiencies, mineral supplementation, ruminants, cattle.

RESUMO.- Muito embora já haja um sólido conhecimento sobre as deficiências minerais e suas consequiências para a saúde e a produtividade dos bovinos no Brasil, paradoxalmente, essas informações, na maioria das vezes, não vêm sendo empregadas

\footnotetext{
${ }^{1}$ Recebido em 15 de junho de 2005.

Aceito para publicação em 6 de julho de 2005 .

${ }^{2}$ Depto Nutrição Animal e Pastagem, Instituto de Zootecnia, Universidade Federal Rural do Rio de Janeiro (UFRRJ), Km 47, Seropédica, RJ 23890000. E-mails: pfpeixoto@terra.com.br, malafaia_ufrrj@yahoo.com.br, tokarnia@ufrrj.br

${ }^{3}$ Escola de Medicina Veterinária, Campus Castanhal, Universidade Federal do Pará, Rua Maximino Porpino 1000, Castanhal, PA 68740-080. Email: diomedes@ufpa.br
}

pelos profissionais das ciências agrárias, que persistem em estimular o uso generalizado das misturas minerais ditas completas. A deficiência de diversos minerais incluídos nestes suplementos, como ferro, cromo, enxofre, entre outros, não ocorre sob condições naturais ou só existe em raras situações muito particulares. O presente tópico aborda os equívocos e problemas relacionados com a suplementação mineral tradicionalmente feita $\mathrm{e}$ discute os principais aspectos da denominada suplementação mineral seletiva, que é fundamentada no fornecimento exclusivo do(s) mineral(is) deficiente(s) e na(s) quantidade(s) necessária(s). Essa alternativa pode permitir uma economia expressiva (por vezes, de até $700 \%$ ) em relação à suplementação mineral comercial normalmente utilizada. De acordo com diversas estimativas, a suplementação mineral pode constituir de 20 a $30 \%$ dos cus- 
tos totais de produção de gado de corte criados em pastagens, daí a importância de diminuir esses gastos. Um ensaio de reversão, no qual um grupo de animais recebe a mistura mineral comercial rotineiramente utilizada na propriedade e outro grupo, o suplemento seletivo, é a melhor opção para discriminar os efeitos (positivos ou negativos) entre dois esquemas de suplementação mineral para uma específica fazenda. Por esse ensaio, investigam-se, racionalmente e por um longo período, os efeitos das duas opções de suplementação mineral em teste, com mínimo risco de perdas econômicas.

TERMOS DE INDEXAÇÃO: Deficiências minerais, suplementação mineral, ruminantes, bovinos.

\section{INTRODUÇÃO}

Sempre que os animais estiverem recebendo dietas com quantidade insuficiente de minerais ou rações desequilibradas que resultem na carência de um ou mais elementos, há que se corrigilas para que os mesmos possam desenvolver seu potencial genético, além de manterem-se saudáveis. Em algumas circunstâncias, a correção do pH do solo e a adubação podem disponibilizar, em maior ou menor quantidade, alguns minerais, além de, eventualmente, melhorar a produção de massa verde da forragem; esse procedimento, porém, é, em geral, anti-econômico em relação à atividade pecuária.

Uma vez que a fertilização das pastagens com compostos minerais, com o objetivo de suprir as necessidades dos animais, via de regra, não é viável, a adequação nutricional dos minerais deve ser realizada pelas diferentes formas de suplementação. Ao nosso ver, alguns conceitos ou práticas, amplamente aceitas e aplicadas rotineiramente, sem questionamentos, precisam ser revistas; nós as denominamos de equívocos sobre suplementação mineral.

\section{Equívocos sobre suplementação mineral}

1) A essencialidade metabólica de um elemento sempre implicaria em sua suplementação obrigatória, via misturas minerais. Essa prática não tem base científica. 0 fato de um determinado elemento mineral ser essencial para os animais ou para o ser humano, não significa que ele deva ser necessariamente suplementado via misturas minerais. Se os alimentos já fornecem quantidades adequadas de determinado(s) elemento(s), não há porque suplementa-lo(s). Essa prática constitui apenas desperdício e pode, inclusive, implicar em menor absorção do(s) mineral(is) realmente necessário(s), pelo fenômeno do antagonismo. Para os ruminantes, numerosos exemplos dessa assertiva podem ser fornecidos: ferro (Fe), cromo $(\mathrm{Cr})$, e enxofre (S), dentre outros, são elementos essenciais, porém, sob condições naturais, dificilmente estão deficientes na dieta de bovinos criados em pastagens. Os estudos para induzir essas deficiências são realizados em condições extremamente especializadas (Underwood \& Suttle, 1999), o que equivale a dizer, praticamente artificiais. Como exemplo, vejamos o caso do ferro, elemento absolutamente essencial: sua deficiência não ocorre em bovinos a menos que estes sejam alimentados exclusivamente com leite (alimento pobre em ferro) ou que sejam administradas na dieta, quantidades absurdas de elementos antagonistas desse elemen- to. No entanto, encontramos ferro na composição da maioria das misturas minerais comercializadas no Brasil. Ao que parece, esta prática deve ser creditada ao equívoco $4, \log 0$ a seguir abordado.

2) A suplementação mineral deveria ser sempre obrigatória em todos os locais ou regiões. Outro equívoco facilmente demonstrável. Embora seja verdade que, no Brasil, tenhamos extensas áreas deficientes em um ou mais minerais, em outras, com exceção da de sódio, que é comum a quase todos os solos distantes do litoral, pode não haver deficiência mineral alguma. Nestas regiões, a suplementação com diversos minerais não traz qualquer benefício para o rebanho, apenas resulta em custos para o pecuarista. Mesmo a deficiência de sódio, praticamente difusa no país, não ocorre em locais onde as águas são salobras com altos teores de sódio ou nas proximidades da orla marítima. Não obstante, em áreas com deficiência de um ou mais elementos, há que se verificar se o(s) mesmo(s) não está(ão) sendo oferecido(s) aos animais por intermédio dos alimentos protéico-energéticos.

Tomemos como exemplo o fósforo, mineral deficiente em grandes extensões do território nacional: Se uma vaca for criada em uma área com solo muito pobre nesse elemento, pode ser necessário suplementar até 6 gramas de fósforo por dia. Ora, basta que esse animal receba aproximadamente $1 \mathrm{~kg} / \mathrm{dia}$ de farelo de trigo, que contém $0,9-1,1 \%$ de fósforo na matéria seca, para que já não haja necessidade de suplementar esse elemento, via mistura mineral. Neste cálculo, ainda não foi computada a quantidade de fósforo que esta vaca estaria ingerindo no volumoso que ela tem que consumir. Adicionalmente, esse animal estaria recebendo, através do farelo de trigo, $8-14 \mathrm{mg}$ de cobre, $0,10-0,13 \mathrm{mg}$ de cobalto e mais de $100 \mathrm{mg}$ de zinco. Ou seja, quando os alimentos protéico-energéticos fornecem os minerais que o animal necessita para a sua mantença e produção, não há menor razão para suplementar com misturas minerais.

3) A suplementação mineral deveria ser sempre praticada, mesmo para animais que recebem dietas energético-protéicas muito pobres. Pensa-se, de forma geral, que a suplementação, via misturas minerais, deveria ser praticada em qualquer situação de forma ininterrupta. No entanto, se levarmos em conta que uma das importantes funções dos minerais é a de serem co-fatores exigidos para o perfeito funcionamento de várias enzimas, cujas funções em reações metabólicas só ocorrem quando existe uma adequada disponibilidade dos substratos (carboidratos, lipídios e protídeos), percebe-se que animais que recebem dietas pobres não se beneficiam da suplementação mineral. Por exemplo, na época seca, quando sabidamente ocorrem grandes restrições qualitativas no valor nutritivo dos pastos (lignificação, menor relação folhas:caules, redução do teor protéico e aumento nos teores dos carboidratos fibrosos indigeríveis), não há efeito benéfico da suplementação mineral sobre o desempenho dos animais, a menos que a dieta, nutricionalmente falando, seja corrigida. Adicionalmente à restrição qualitativa, em muitos casos existe também a quantitativa, traduzida pela menor dis- 
ponibilidade de matéria seca para os animais. Ou seja, a suplementação mineral na época da seca só deve ser realizada nas áreas deficientes se, e somente se, as necessidades energético-protéicas dos animais estiverem sendo atendidas. O mesmo raciocínio vale para quaisquer outras circunstâncias, nas quais a ingestão de carboidratos e de proteína estiver muito aquém das necessidades.

4) Quanto maior o número de elementos incluídos na composição de uma mistura mineral, melhor ela seria. Trata-se de uma pressuposição equivocada que pode até resultar em prejuízos à saúde ou à produção dos animais, uma vez que elementos não-deficientes na dieta e incluídos na mistura mineral podem antagonizar com outros realmente necessários. Por exemplo, ao incluir sulfato de ferro em uma mistura mineral estamos reduzindo a absorção do fósforo e de cobre. Por outro lado, a inclusão de elementos como cromo, vanádio, níquel, entre outros, nas misturas minerais, via de regra, não traz qualquer benefício, pelo contrário, pode ser até prejudicial, em função do antagonismo entre os elementos, como vimos em relação ao ferro e ao cobre. Um exemplo que ilustra essa assertiva ocorreu no município de Rondonópolis, Mato Grosso. Há cerca 25 anos, um fabricante de misturas minerais de São Paulo houve por bem incluir elevados níveis de ferro no seu produto, sob a incompreensível alegação de que esse procedimento haveria de controlar a haemoncose em bovinos. Ao cabo de alguns meses, os bovinos desenvolveram marcadas lesões ósseas por deficiência de fósforo, determinadas pelo antagonismo do ferro com esse elemento.

Não conhecemos qualquer razão para incluir ferro em misturas minerais para nenhuma categoria de bovinos criados em condições naturais.

5) Quanto maior o teor do(s) mineral(is) na mistura melhor seria a qualidade desse suplemento. Também não encontramos base científica para suportar essa inferência, pois, primeiramente, há que se estimar quanto do(s) elemento(s) o animal necessita e ingere por dia via alimentos protéicoenergéticos. Por exemplo, se o animal carece de suplementação diária de $1,5 \mathrm{~g}$ de fósforo, não há razão para suplementar o dobro ou o triplo desta quantidade, uma vez que o excedente perdido custa caro. $\mathrm{O}$ argumento segundo o qual, agindo dessa forma, estaríamos elevando o nível de fósforo nas pastagens, via perdas fecais, não se sustenta, uma vez que essa prática seria uma forma muito mais cara de fertilizar os pastos com o fósforo.

6) Quanto maior o consumo diário de uma mistura mineral, melhor seria a qualidade dessa mistura. A maior ou menor ingestão de uma mistura mineral reflete, antes de tudo, seu teor de cloreto de sódio (sal). Uma vez adaptados, os bovinos não ingerem mais de $35 \mathrm{~g}$ de sal por dia, mas se reduzirmos os teores dessa substância à metade ou a $25 \%$, ou menos, como ocorre com algumas misturas minerais, os animais podem ingerir até mais de $120 \mathrm{~g}$ dessas misturas minerais diariamente! Isto é péssimo para o proprietário que irá pagar, sem necessidade, pelas 34 vezes a mais que os bovinos irão ingerir da mistura mineral comercial, já suficientemente cara.
7) A formulação e a preparação de um suplemento mineral não deveriam ser feitas pelos técnicos nas fazendas. Não encontramos justificativa para essa pressuposição, pois, ao nosso ver, qualquer profissional das ciências agrárias com bons conhecimentos de nutrição de ruminantes pode perfeitamente formular e preparar um suplemento mineral na fazenda. Alguns cuidados, porém, devem ser tomados na compra dos ingredientes, na mistura e homogeneização dos elementos com o cloreto de sódio.

\section{A SITUAÇÃO DA SUPLEMENTAÇÃO MINERAL NO BRASIL}

Em nosso país existe uma grande disparidade em termos de sistemas de exploração em pecuária de corte e de leite. Em algumas regiões, os bovinos são criados em condições que nada ficam a dever às dos países desenvolvidos, já em outras, verificase um primitivismo muito grande na criação dos animais.

No que diz respeito à suplementação mineral, hoje nos deparamos com as seguintes situações: (1) Parte dos pecuaristas opta pela utilização de uma mistura mineral comercial (MMC); (2) Parte compra uma MMC formulada com base no pressuposto de que análises de solo e de forrageiras de sua propriedade possam determinar com exatidão a quantidade de minerais necessária a ser suprida aos animais; (3) Outra parte fornece apenas cloreto de sódio ( $\mathrm{NaCl}$ ); (4) Uma pequena parcela dos pecuaristas não fornece qualquer suplemento mineral ao rebanho; (5) Outro grupo de pecuaristas suplementam os animais de maneira muito irregular e descontínua com MMC ou com o cloreto de sódio; (6) Como as misturas minerais são insumos caros, alguns proprietários diluem essas misturas com o sal comum, o que obviamente reduz a concentração dos outros minerais nesse preparado. Neste caso, dependendo da diluição, mesmo que os teores dos minerais na mistura original sejam adequados, em algumas situações haverá necessidade de corrigir elementos deficitários.

\section{Principais problemas relativos à suplementação mine- ral no país}

a) Quantidades insuficientes. É preciso ter em mente que algumas MMC não contêm quantidades suficientes de um ou mais minerais para suprir as exigências dos animais criados em algumas regiões do Brasil. Podemos exemplificar com o que vem acontecendo em algumas áreas do Estado do Pará, onde há verdadeiras mortandades por deficiência de fósforo e/ou de cobalto, apesar da utilização de misturas minerais comerciais ser a prática comum na região. Nos últimos anos, já verificamos a elevação dos teores dos elementos, especialmente do fósforo, em algumas misturas comercializadas nesta e em outras regiões do país. Se tomarmos como exemplo algumas MMCs que contém $40 \mathrm{gP} / \mathrm{kg}$, vamos verificar que, embora sejam adequadas para regiões de leve ou moderada deficiência de fósforo, com certeza deixam a desejar nas áreas de deficiência acentuada, onde pode ser necessária a elevação dos teores de fósforo para $90 \mathrm{gP} / \mathrm{kg}$.

b) Baixa concentração de cloreto de sódio na MMC. Outro fenômeno que vem se difundindo é a redução das concentrações de cloreto de sódio $(\mathrm{NaCl})$ em algumas misturas minerais. Considerando-se que os bovinos adultos ingerem, depois 
de adaptados, no máximo 30-35g/dia de cloreto de sódio, misturas minerais elaboradas com baixos teores de $\mathrm{NaCl}$, estimulam o aumento da ingestão diária dessa mistura. Essa substituição é geralmente feita com calcáreo, que é barato e não restringe o consumo diário da mistura mineral. Em um levantamento feito a partir de cálculos baseados nas informações do teor de $\mathrm{Na}(\mathrm{g} / \mathrm{kg})$ em 15 misturas minerais, foram observados valores médios de $38,2 \%$ de $\mathrm{NaCl}$, com valor máximo de $65 \%$ e mínimo de $25 \%$ (Malafaia \& Peixoto 2003). Esses níveis baixos podem proporcionar consumos diários maiores do que $120 \mathrm{~g} /$ dia, o que representa custos 3 até 4 vezes maiores que o necessário (Malafaia et al 2004).

c) Ingestão insuficiente (ou não-ingestão) da mistura mineral ou do cloreto de sódio. Esse problema ocorre basicamente nas seguintes situações:

- Impedimento do acesso ao cocho por questões de hierarquia. Sabe-se que $8-10 \%$ dos bovinos podem não ter acesso ao cocho de sal mineral em função da estratificação hierárquica que se verifica no rebanho. Em algumas situações, quando coexistem animais de diferentes idades ou de diferentes pesos, esses índices podem atingir $25 \%$ ou mais.

- Falta de espaço no cocho que permita a ingestão. Preconiza-se pelo menos $4-8 \mathrm{~cm}$ lineares de espaço no cocho por cada animal. Temos encontrado situações em que um cocho de 1 metro é utilizado para mais de 100 animais, o que, obviamente, é inadequado.

- Disponibilização insuficiente ou ocasional da mistura mineral. Muitas vezes não se leva em conta as quantidades de sal que o bovino necessita ingerir diariamente. A disponibilidade da mistura mineral deve ser constante e de tal forma que permita a ingestão diária de aproximadamente $30 \mathrm{~g} /$ dia de cloreto de sódio por animal adulto.

- Localização dos cochos. Cochos muito distantes de áreas sombreadas e em local pouco pastejado, influenciam no consumo diário do suplemento mineral, uma vez que os animais tendem a não se deslocar até este local para ingerir o suplemento. Os cochos devem ser, de preferência, localizados perto das aguadas e em área sombreada onde normalmente os animais terão conforto térmico para que possam ingerir o suplemento a qualquer hora do dia.

- Cobertura do cocho. É de fundamental importância para se manter a qualidade da mistura mineral e seu posterior consumo. O sal $(\mathrm{NaCl})$, pela sua elevada higroscopicidade, "empedra", pelo efeito do sereno, o que acarreta redução da ingestão do suplemento. O ideal é que todos os cochos sejam cobertos e protegidos das chuvas com vento.

- A diluição do núcleo mineral ou da mistura mineral com o cloreto de sódio. Muitos produtores, por pagarem caro pelos "núcleos" ou pelas misturas minerais, os diluem 5-10 vezes mais do que a recomendação dos fabricantes.

- A altura do cocho em relação ao solo. Também é fator importante pois, na maioria das vezes, os cochos são colocados juntos ao chão, possibilitando que os animais pisem, defequem ou urinem em cima do cocho. Isto representa perda econômica e reduz a ingestão do suplemento mineral. A altura do cocho deve ser variável de acordo com a categoria animal que está no pasto. A altura do cocho deve ser de $50-60 \mathrm{~cm}, 70-80 \mathrm{~cm}$ e $100 \mathrm{~cm}$ para vacas com cria ao pé, animais de recria e engorda, respectivamente.

d) Diluição das fontes de alguns elementos. Merece menção a prática de "batizar" fontes de alguns elementos, como tem sido feito com o sulfato de cobalto. Tal procedimento implica em não poder resolver o problema da deficiência desse elemento, onde ela porventura ocorrer. Em muitos locais, o sulfato de cobalto é comercializado com um teor de $20 \%$ ou menos. Em algumas cooperativas pode-se ter a informação de que o produto foi mesmo diluído, já em outras, tal informação inexiste. Embora os bovinos necessitem de aproximadamente $1 \mathrm{mg}$ de cobalto por dia, em áreas de acentuada carência desse elemento, as misturas minerais com teores muito baixos, podem não ser suficientes para suprir a carência dos animais nesse elemento.

Considerando os equívocos sobre suplementação mineral e com o objetivo de diminuir o seu elevado custo, temos proposto uma forma alternativa denominamos de suplementação mineral seletiva (Peixoto et al. 2003). Na verdade esse conceito não é novo, pois há mais de 40 anos, se advoga que só devem ser fornecidos os minerais sabidamente deficientes no Brasil, a saber, sódio, fósforo, cobre, cobalto e eventualmente selênio e zinco (Tokarnia et al. 2000). Essa suplementação mineral seletiva nada mais é do que a amplificação desse conceito: trata-se da administrar apenas o(s) mineral(is) deficiente(s) e nas quantidades necessárias, de acordo com o grau de deficiência na propriedade.

e) Como suplementar minerais em locais onde os animais não ingerem sal (cloreto de sódio) voluntariamente. Em áreas próximas da orla marítima ou em regiões de águas salobras ou de solos ricos em sódio (salinas), o problema da suplementação mineral pode residir no fato de bovinos ingerirem pouco ou simplesmente não ingerirem a mistura mineral, pois já receberam através do capim ou da água o sódio de que necessitam. Nessas condições devem-se utilizar outras alternativas, para que os animais recebam o(s) mineral(is) de que precisam Via alimentos - alimentos de boa palatabilidade como farelo de trigo, de milho ou de soja podem ser utilizados como forma de induzir a ingestão (do)s mineral(is) deficiente(s); nesse caso, o cloreto de sódio ( $\mathrm{NaCl}$ ) deve ser adicionado para funcionar como um "freio", que vai evitar a ingestão de quantidades excessivas do alimento ou do(s) outro(s) mineral(is) que deverá(ão) ser veiculado(s) através do alimento. A questão fundamental é determinar se ou até que ponto os animais ingerem $\mathrm{NaCl}$. Se, por exemplo, os animais ingerem voluntariamente apenas $10 \mathrm{~g}$ por dia de $\mathrm{NaCl}$, essa quantidade deve ser levada em conta para a adição dos outros minerais. Se, em outra situação, não ingerem nada de $\mathrm{NaCl}$, a indução da ingestão da mistura mineral será feita por meio de alimento cuja ingestão será regulada pela adição de maiores ou menores quantidades de $\mathrm{NaCl}$, conforme o tipo de alimento utilizado. $\mathrm{O}$ farelo de trigo pode ser utilizado com esse propósito por ser muito palatável e relativamente barato. De qualquer maneira, a introdução deverá ser feita de acordo com testes realizados, na própria fazenda, levando-se em conta uma quantidade mínima de alimento/mistura mineral ca- 
paz de servir de veículo para que os animais tenham suas exigências em minerais atendidas. Via injeções - injeções de cobre podem constituir uma boa alternativa pra suplementação de rebanhos carentes nesse elemento. Via balas - bastante utilizadas em países como a Austrália, as balas funcionam bem para a suplementação, em especial, de cobalto. Infelizmente, porém, até algum tempo atrás, as mesmas não estavam disponíveis no mercado brasileiro.

A partir da exposição acima podemos apresentar as seguintes regras básicas da suplementação mineral seletiva (SMS).

\section{REGRAS BÁSICAS DA SUPLEMENTAÇÃO SELETIVA (SMS)}

1) Não suplementar minerais se não há sinais diretos ou indiretos de deficiência mineral;

2) A suplementação mineral deve ser ajustada ao nível de produção;

3) As necessidades da suplementação mineral variam com a área (região), época do ano e com o manejo alimentar do rebanho;

4) Pouco adianta suplementar minerais sem a prévia adequação protéica-energética da dieta e sem uma adequada disponibilidade de volumoso, isto é, antes de suplementar com minerais, deve-se verificar se o animal ingere energia e proteína suficientes para desenvolver seu potencial genético;

5) A formulação mineral deve ser feita caso a caso, isto é, fazenda a fazenda;

6) A introdução da suplementação mineral seletiva sempre deve ser feita mediante estudos comparativos (ensaio de reversão);

7) Estar sempre atento ao risco inerente de toxicidade dos minerais, em especial com relação ao cobre e ao selênio;

8) Suplementar minerais em excesso equivale a "jogar dinheiro fora".

\section{IMPLANTAÇÃo DA SUPLEMENTAÇÃO SELETIVA}

A suplementação mineral seletiva pode ser implantada de diversas formas, mas sempre mediante testes comparativos com a suplementação mineral precedente (quando ela vinha sendo feita). Lembramos sempre que qualquer que seja o método de implantação, deve-se ter todo cuidado para evitar qualquer perda econômica.

Em fazendas onde não exista nenhum tipo de suplementação mineral ou o proprietário apenas fornece cloreto de sódio aos animais, a questão central para se fazer o sal seletivo, é $a$ identificação correta de quais minerais estão "faltando" nos pastos de uma propriedade. Isso só pode ser feito por um profissional que tenha adequados conhecimentos sobre clínica e nutrição mineral dos bovinos. Apenas esse profissional é capaz de reconhecer, nos animais, quais minerais que porventura estão deficitários em sua dieta e formular um suplemento mineral seletivo capaz de corrigir essa falta.

Em fazendas onde já se utiliza uma MMC, uma maneira de implantar a suplementação mineral seletiva é através de um "ensaio de reversão", isto é, estabelecemos um protocolo experimental simples, no qual um grupo de animais permanece recebendo a MMC rotineiramente utilizada, enquanto outro grupo irá rece- ber um SMS proposto com base no exame clínico-epidemiológico do rebanho, bem como no manejo nutricional dos animais. Findo o ensaio de reversão, na ausência de efeitos negativos sobre o desempenho e a saúde dos animais, o pecuarista deverá adotar a opção mais barata (Malafaia et al. 2004).

Ressaltamos que a avaliação comparativa entre as vantagens e desvantagens da suplementação comercial e da seletiva, além de levar em conta os aspectos econômicos, o manejo e a eficiência no tratamento e profilaxia de estados carenciais, refere-se sempre apenas à propriedade onde se está sendo feita a experimentação.

O conhecimento geral sobre a distribuição das áreas de deficiência mineral no Brasil pode facilitar bastante a implantação da suplementação mineral seletiva. Por outro lado, há que se reconhecer que a "mineralização" convencional dos rebanhos com as MMC é mais cômoda, pois não implica em formular e preparar a mistura. É possível que em algumas regiões não sejam encontrados os ingredientes para o preparo do suplemento mineral seletivo. Também há que se tomar cuidado (ver equivoco 5) para que não haja erros na formulação e no preparo do sal mineral seletivo (SMS), que poderiam redundar na não-resolução do estado carencial ou na intoxicação dos animais. Porém, o cálculo correto e a boa homogeneização dos ingredientes evitam esses riscos.

\section{ASPECTOS ECONÔMICOS DA SUPLEMENTAÇÃO MINERAL SELETIVA}

Obviamente que não se pode perder de vista o impacto que a suplementação mineral representa nos custos operacionais no empreendimento pecuário. Na pecuária moderna praticada hoje em algumas regiões ou micro-regiões do país, reduzir custos e enxugar despesas tornam-se essenciais para melhorar a rentabilidade ou até manter-se viável nas épocas de crises. Em qualquer situação, seja na pecuária de alta tecnologia, seja na praticada empiricamente, é óbvio que os gastos desnecessários devem ser suprimidos. Estima-se que a suplementação mineral pode constituir 20-30\% dos custos totais de produção de gado de corte (Souza 1985, Magnoli Costa 2004). No Brasil, depois da amortização do capital, os gastos com suplementação mineral representam o segundo ou terceiro maior componente dos custos totais de produção (Lopes 1998, Costa 2004).

Através de levantamentos de preços de suplementos minerais comerciais em diversos estados do país, verificamos que a SMS tem um custo, em média, 3 a 4 vezes menor do que aquele verificado na suplementação mineral convencional. Se levarmos em consideração que os bovinos ingerem, em alguns casos, mais de 120 gramas de MMC por dia, esses gastos podem ser ainda maiores, ou seja, os gastos com as MMC podem passar de $700 \%$ dos custos com a SMS.

\section{QUELATOS}

Mais recentemente, ao final da década de 1980, surgiram os ditos "minerais orgânicos" ou quelatos, uma forma de suplemento mineral que, pretensamente, aumentaria a produtividade dos animais. Essas substâncias teriam grandes vantagens sobre a forma convencional de "mineralização" por serem de elevada 
absorção, mais biodisponíveis e menos tóxicas; adicionalmente, não haveria interação (antagonismos) entre elas e outros minerais ou nutrientes (gorduras e fibras da dieta). Geralmente tratase de compostos produzidos por quelação (ligação) entre metais e amino-ácidos. Por definição são íons metálicos ligados quimicamente a uma molécula orgânica, formando estruturas únicas de estabilidade e de alta biodisponibilidade mineral.

De fato, não parece haver dúvidas de que os "minerais orgânicos" têm biodisponibilidade maior que os minerais na forma inorgânica. A questão central, ao nosso ver, reside na pergunta: esses compostos são economicamente viáveis, ou seja, sua utilização aumenta o lucro do pecuarista?

Nesse ponto, somos da mesma opinião de Underwood \& Suttle (1999): "As afirmações de que as formas queladas de microelementos são mais eficazes que os simples minerais inorgânicos deveriam ser ignoradas até que sejam publicadas evidências, em periódicos cientificamente idôneos, de que benefícios econômicos e nutricionais sejam consistentemente obtidos. Segundo Suttle (1994), como fonte de cobre, não há evidência de que esses complexos quelados sejam superiores. Mais ainda, o fato da quelação ser vantajosa para um elemento (por exemplo, o cromo, que por sinal, só excepcionalmente, está deficiente na dieta) não quer dizer que seja proveitosa para outros. As evidências de que a quelação altera a forma ou a distribuição do elemento quelado na fase inicial da digestão (rúmen) não é prova de beneficio nutricional (grifo nosso). Também a evidência de que a quelação aumenta a concentração tecidual de determinados elementos, cuja captação é regulada pela necessidade (do elemento) - por exemplo, o zinco - pode indicar apenas um desvio do mecanismo homeostático e, novamente, não fornece provas de efeito benéfico nutricional.

Por outro lado, esses compostos são bem menos tóxicos que os minerais na forma inorgânica. Desde que sejam garantidas, porém, homogeneização correta e nível adequado do(s) mineral(is) no preparo da mistura mineral, essa vantagem dos "minerais orgânicos” perde-se pelo seu custo evidentemente mais elevado.

\section{CONCLUSÕES}

Não resta dúvida que, no Brasil, as deficiências minerais, de uma forma geral, têm ampla distribuição e são responsáveis por sérios prejuízos econômicos. Boa parte dos veterinários, zootecnistas e pecuaristas está ciente dessa situação. A questão que deve ser agora observada, porém, é como suplementar o rebanho da forma mais objetiva possível, isto é, levando-se em conta, de forma conjunta, a sanidade, a produtividade e o aspecto econômico.

Se, por um lado, foi positiva a massificação, por parte da mídia, das informações sobre a necessidade de suplementar minerais ao rebanho, uma vez que jogou um "foco de luz" sobre a importância das enfermidades ou distúrbios associados às deficiências, por outro lado, redundou, em geral, em formas inadequadas de suplementação. Maneiras de corrigir ou minimizar o problema, como a suplementação mineral seletiva, podem ser, eventualmente, implantadas, pois resultam em substancial diminuição dos custos de produção, sem reduzir a produtividade, nem afetar a saúde dos animais.

Estudos comparativos sobre o efeito dos minerais na produção e na sanidade, em diferentes situações, também deveriam ser incentivados, como forma de demonstrar os onerosos equívocos que existem na forma de suplementar minerais aos bovinos no Brasil. Deve-se, contudo, deixar bem claro que mudanças na suplementação mineral, devem ser feitas com cuidado, caso a caso, mediante os chamados ensaios de reversão.

\section{REFERÊNCIAS}

Lopes H.O.S. 1998. Suplementação de Baixo Custo para Bovinos. EmbrapaCPAC, Brasília, DF. 107p.

Costa R. M. 2004. Dados não publicados (www. exitorural.com.br).

Malafaia P. \& Peixoto P.V. 2003. Dados não publicados (Univ. Fed. Rural do Rio de Janeiro).

Malafaia P., Peixoto P.V., Gonçalves J.C.S., Moreira A.L., Costa D.B.P. \& Correa W.S. 2004. Ganho de peso e custos em bovinos de corte submetidos a dois tipos de suplementos minerais. Pesq. Vet. Bras. 24(3):46-50.

Peixoto P.V., Malafaia P., Miranda L.V., Canella C.F.C., Canella Filho C.F.C. \& Vilas Boas F.V. 2003. Eficiência reprodutiva de matrizes bovinas de corte submetidas a três diferentes tipos de suplementação mineral. Pesq. Vet. Bras. 23(3):125-130.

Souza J.C. 1985. Formação do Preço do Suplemento Mineral. EmbrapaCNPGC Informa 2(2):1-2.

Suttle N.F. 1994. Meeting the copper requirements of ruminants, p.173187. In: Garnsworthy P.C. \& Cole D.J.A. (ed.) Recent Advances in Animal Nutrition, Nottingham University Press, Nottingham. (Cit. Underwood E.J. \& Suttle N.F. 1999)

Tokarnia C.H., Döbereiner J., Peixoto P.V. \& Canella C.F.C. 2000. Deficiências minerais em animais de fazenda, principalmente bovinos. Pesq. Vet. Bras. 20(3):127-138. (Separata)

Underwood E.J. \& Suttle N.F. 1999. The Mineral Nutrition of Livestock. CABI Publishing, London. 609p. 